\section{Nanometre}

$(\mathrm{nm})$. A unit of measurement equal to one billionth of a metre. It is the unit of measurement for many molecular structures that are relevant to immunology.
'Michigan Nanotechnology Institute for Medicine and Biological Sciences, University of Michigan Medical School, 9220Medical Sciences Research Building III, 1150 West Medical Center Drive, Ann Arbor, Michigan 48109-5648, USA ${ }^{2}$ Department of Internal Medicine, University of Michigan Medical School, 9220Medical Sciences Research Building III, 1150 West Medical Center Drive, Ann Arbor, Michigan 48109-5648, USA.

${ }^{3}$ NanoBio Corporation, 2311 Green Road, Suite A, Ann Arbor, Michigan 48105, USA.

"These authors contributed equally to this work.

Correspondence to D.M.S. e-mail:

smitdoug@med.umich.edu doi:10.1038/nri3488

Corrected online 25July 2013

\title{
Applications of nanotechnology for immunology
}

\section{Douglas M. Smith ${ }^{1,2 *}$, Jakub K. Simon ${ }^{3 *}$ and James R. Baker Jr ${ }^{1,3}$}

Abstract | Nanotechnology uses the unique properties of objects that function as a unit within the overall size range of 1-1,000 nanometres. The engineering of nanostructure materials, including nanoparticles, nanoemulsions or nanotubules, holds great promise for the development of new immunomodulatory agents, as such nanostructures can be used to more effectively manipulate or deliver immunologically active components to target sites. Successful applications of nanotechnology in the field of immunology will enable new generations of vaccines, adjuvants and immunomodulatory drugs that aim to improve clinical outcomes in response to a range of infectious and non-infectious diseases.

Biological molecules such as oligonucleotides, polysaccharides, and proteins that function as antigens, allergens or pathogen-associated molecular patterns (PAMPs) are of nanometre (nm) size ${ }^{1,2}$ (TABLE 1). In this Review we discuss how the size, shape, charge, porosity and hydrophobic properties of a compound influence its effects on the immune response and how nanotechnology can be used to engineer each of these properties (FIG. 1). We review the role of nanotechnology with respect to its applications in the development of vaccines and immunosuppressive agents, and we highlight how the manipulation and control of objects at the nanoscale level (BOX 1) can contribute to our understanding, as well as to our targeting, of the immune response. The field of nanotechnology is vast, therefore including all of the relevant studies is beyond the scope of this Review. However, we provide examples of selected studies that show the broad range of immunological applications of nanotechnology.

\section{Nanotechnology in vaccination}

Inactivated vaccines typically incorporate adjuvants, which are substances that enhance the quantity and the quality of the cellular and humoral immune responses generated against the antigens that are included in the vaccine. Nanoparticles provide adjuvant activity by enhancing the delivery of antigens to the immune system or by potentiating innate immune responses (FIG. 2). We discuss some of these nanotechnologies in the section below (FIG. 3; TABLE 2). Some nanotechnologies that improve vaccine efficiency, such as virus-like particles (VLPs) and MF59 (Novartis), have been used for decades, whereas others are still at the early stages of development.
VLP-based vaccines. VLPs are diverse and highly versatile nanoparticles $(20-100 \mathrm{~nm}$ in size) that have been used in vaccines against infectious diseases and cancer (TABLE 2). More recently, VLPs have been used in vaccines that aim to protect against chronic diseases that have an inflammatory basis, such as hypertension, Alzheimer's disease and rheumatoid arthritis, and also in vaccines against drug addiction ${ }^{3,4}$. VLPs used in vaccines can be broadly divided into two classes: in one class, VLPs that comprise the viral protein subunits that form the viral capsid in nature; and in another class, synthetic VLPs that are derived by the chemical synthesis of pre-designed subunits as described below.

VLPs can be distinguished from viruses by their absence of genetic material and their inability to replicate or to undergo genetic recombination. More than 20 to 30 different enveloped or non-enveloped VLPs are currently in preclinical and clinical development ${ }^{4}$. VLPs can be produced either without modification or by genetically engineering the viral capsid subunit by bioconjugation of the viral capsid subunit with antigenic peptides or other ligands or by site-directed mutagenesis of the intact VLP to create a functional scaffold for multivalent surface presentation of antigens. Other structures can be incorporated into VLPs, such as Toll-like receptor (TLR) ligands, celltargeting moieties or other biologically active mediators, to augment vaccine efficacy. In human clinical trials, VLPs loaded with synthetic A-type CpG-oligonucleotides (CpGODNs) and peptide epitopes derived from melanomaassociated antigens, such as melanoma antigen recognized by T cells 1 (MART1), have been shown to activate multifunctional central memory $\mathrm{T}$ cells and cytotoxic $\mathrm{T}$ lymphocytes (CTLs) that produce interferon- $\gamma$ (IFN $\gamma)$, tumour necrosis factor- $\alpha$ (TNF) and interleukin-2 (IL-2) ${ }^{5}$. 
Table 1 | Biological scale of immunologically relevant materials

\begin{tabular}{|llr|}
\hline Structure & Size & Refs \\
\hline Molecules & & 1,2 \\
\hline DNA & $1-3 \mathrm{~nm}$ & 125 \\
\hline Polysaccharides & $200-1,000 \mathrm{~nm}$ & 126 \\
\hline Proteins & $2-10 \mathrm{~nm}$ & \\
\hline Receptors & & 127 \\
\hline TLRs & $2-10 \mathrm{~nm}$ & 128 \\
\hline Antibodies & $10-15 \mathrm{~nm}$ & 129 \\
\hline TCRs & $10-15 \mathrm{~nm}$ & 130 \\
\hline Pathogens & & 130 \\
\hline Viruses & $10-200 \mathrm{~nm}$ & 131 \\
\hline Bacteria & $0.1-8 \mu \mathrm{m}$ & 132 \\
\hline Fungi & $1-100 \mu \mathrm{m}$ & \\
\hline Protozoa & $1-100 \mu \mathrm{m}$ & 133 \\
\hline Cells & & 134 \\
\hline Dendritic cells & $10-22 \mu \mathrm{m}$ & 135 \\
\hline Macrophages & $10-22 \mu \mathrm{m}$ & 136 \\
\hline B cells & $7-10 \mu \mathrm{m}$ & 137 \\
\hline T cells & $7-10 \mu \mathrm{m}$ & 138 \\
\hline Neutrophils & $8-15 \mu \mathrm{m}$ & \\
\hline Eosinophils & $10-12 \mu \mathrm{m}$ & \\
\hline CCR,Tcell & & \\
\hline
\end{tabular}

TCR, T cell receptor; TLR, Toll-like receptor.

Several of the advantages of using VLPs and other nanoparticles in vaccines are related to the unique nanodimensional size, symmetrical shape, uniformity and stable structure of the assembled nanoparticles, which closely resemble native viruses. These nanoparticles have been used to enable the preferential uptake of vaccine antigens by antigen-presenting cells (APCs). Notably, smaller nanoparticles $(25-40 \mathrm{~nm} \text { in size })^{6}$ penetrate tissue barriers and traffic to the draining lymph nodes more rapidly than larger nanoparticles (greater than $100 \mathrm{~nm}$ in size), which are typically retained by cells at the site of injection and which need to be taken up and trafficked by dendritic cells (DCs) to facilitate their transport to the lymph nodes ${ }^{6,7}$ (FIG. 2). As such, smaller nanoparticles might lead to more effective activation of adaptive immune responses ${ }^{7-9}$.

In combination with specific cell-targeting strategies, nanoparticles also seem to be more effective than microparticles at enhancing antigen uptake by cells of the immune system; for example, when nanoparticles or microparticles were coated with DC-specific ICAM3-grabbing non-integrin (DC-SIGN; also known as CD209)-specific monoclonal antibody to target them to DCs, the DC-SIGN-coated nanoparticles were effectively targeted to DCs in a mixed population of human blood cells, whereas the DC-SIGN-coated microparticles were endocytosed in a nonspecific manner ${ }^{10}$. Furthermore, whereas most extracellular proteins that are taken up by DCs are processed and presented via the MHC class II pathway, the uptake of nanoparticles such as VLPs promotes DC activation and the presentation of antigens on both MHC class I and MHC class II molecules. Importantly, this leads to the priming of both antigen-specific $\mathrm{CD}^{+}$and $\mathrm{CD}^{+}{ }^{+} \mathrm{T}$ cells ${ }^{4,11-14}$ (FICS 2,3).

Two prophylactic VLP-based vaccines have been licensed worldwide: one prevents hepatitis $B$ virus (HBV) infection and the associated risk of hepatocellular carcinoma ${ }^{15-17}$; the other prevents human papillomavirus (HPV) infection and its sequela, cervical cancer ${ }^{18}$. The use of a recombinant protein engineered to self-assemble into a VLP in the recombinant HBV vaccine was a major advance in safety, and the plasmabased HBV vaccine has now been replaced ${ }^{15}$. However, this first generation of VLP-based vaccines requires adjuvants for optimal immunogenicity in healthy individuals and is not highly effective in high-risk populations such as immunosuppressed patients and elderly individuals. In addition, the HBV vaccines are highly effective as a prophylactic vaccine but ineffective as a therapeutic vaccine. The formulation of $\mathrm{HBV}$ vaccines with aluminium (alum) adjuvants is a major limitation with respect to the effective induction of T cellmediated immunity against chronic hepatitis $\mathrm{B}$, as alum predominantly activates $\mathrm{T}$ helper $2\left(\mathrm{~T}_{\mathrm{H}} 2\right)$-type immune responses ${ }^{19,20}$. The HPV vaccine that has more recently been developed uses monophosphoryl lipid A (MPL) added to alum as an adjuvant to induce a $\mathrm{T}_{\mathrm{H}} 1$-type immune response and CTLs that are associated with antiviral immunity ${ }^{19,21-25}$.

Although current VLP-based vaccines are only prophylactically efficacious but have limitations for use in therapeutic applications, these vaccines have an excellent safety record ${ }^{26}$. Recombinant HBV vaccines have been licensed since 1986 and hundreds of millions of doses have been administered worldwide. Pitfalls of advancing any new technology, such as novel adjuvants that enhance the immune response, include the potential risks of inducing rare, but serious, adverse reactions that only become evident after the evaluation of hundreds of thousands of individuals. Concerns about the induction of autoimmune diseases, including multiple sclerosis, Guillain-Barré syndrome and rheumatoid arthritis, following VLPbased vaccination have been raised but have not been confirmed ${ }^{27}$. In a systematic review of the association between multiple sclerosis and hepatitis B vaccination, 1 out of 12 studies reported an association. The authors of that review concluded that there was insufficient evidence to modify vaccination schedules and called for additional studies to be carried out ${ }^{27}$. VLPs and other emerging nanoparticle-based technologies provide new strategies to enhance the induction of potent, long-lasting and potentially broadly reactive (multiclade neutralization) humoral and cellular immune responses that will be crucial to achieve protection and therapy against chronic infections, rapidly mutating pathogens such as influenza and HIV-1, and late-stage malignant diseases as discussed below. These benefits must be balanced against any real or perceived risks so that the use of the vaccine is high and a benefit to public health is achieved. 
a

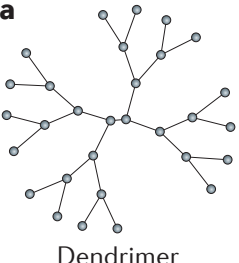

e

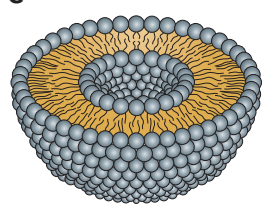

Liposome b

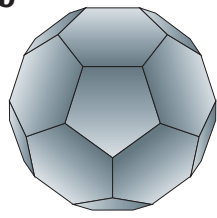

Spherical fullerene

f

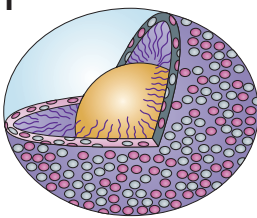

Oil-in-water emulsion c

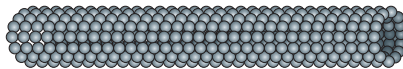

Cylindrical fullerene

g

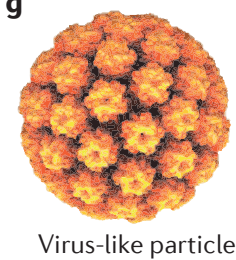

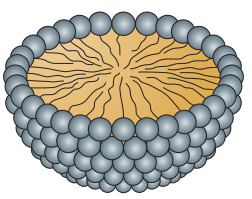

Micelle

h

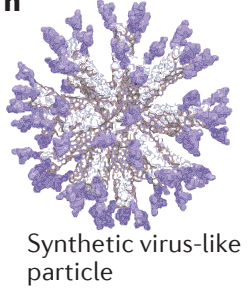

i

\begin{tabular}{|c|c|c|c|c|}
\hline Size & $<5 \mathrm{~nm}$ & $10-20 \mathrm{~nm}$ & $50-100 \mathrm{~nm}$ & $>150 \mathrm{~nm}$ \\
\hline Nanoparticle & Dendrimer & Polymer & DNA polyplex & Liposome \\
\hline Bioactivity & $\begin{array}{l}\text { Partition like small } \\
\text { molecules and filter } \\
\text { through the kidney }\end{array}$ & $\begin{array}{l}\text { Escape the vasculature, } \\
\text { infiltrate the tissues and } \\
\text { lymphatics like proteins }\end{array}$ & $\begin{array}{l}\text { Penetrate the mucosal } \\
\text { membranes and the skin } \\
\text { and are taken up into cells. }\end{array}$ & $\begin{array}{l}\text { Taken up mainly } \\
\text { into phagocytic } \\
\text { cells }\end{array}$ \\
\hline
\end{tabular}

Figure 1 | Examples of nanotechnologies applied to immunoregulation. Nanotechnologies that can be applied to immunoregulation include nanoparticles (parts $\mathbf{a}-\mathbf{c}$ ), nanoemulsions (parts $\mathbf{d}-\mathbf{f}$ ) and virus-like particles (parts $\mathbf{g}-\mathbf{h}$ ). Nanoparticles include dendrimers which branch out (part a), carbon molecules known as spherical fullerenes (part b) and cylindrical carbon molecules known as cylindrical fullerenes (part c). Nanoemulsions incorporate immiscible components such as oil and water that might form amphiphilic molecules such as micelles (part d), liposomes with a lipid bilayer (part e) and oil-in-water emulsions (part f). Virus-like particles are self-assembled structures composed of one or more viral capsid proteins (part $\mathbf{g}$ ), whereas synthetic virus-like particles are self-assembled from chemically synthesized components (part h). Examples of the relationship between nanoparticle size and bioactivity are shown in (part i).

Synthetic VLPs. The development of fully synthetic VLPs using chemically synthesized lipopeptide monomers ${ }^{28}$ to enhance nanoparticle assembly and to stabilize the three-dimensional conformational structure of protein antigens provides an intriguing vaccine strategy to stimulate neutralizing antibodies against HIV-1. In contrast to enveloped HIV-1 VLPs, which are limited by low Env density per virion ${ }^{4,29,30}$, or to the self-assembling peptide nanoparticles (SAPNs) described below, the synthetic approach does not require recombinant DNA technology or the expression and the purification of the monomer proteins from producer cells. Lipopeptidebased synthetic VLPs (20-30 $\mathrm{nm}$ in size) have been used to repetitively display a peptide-mimetic epitope derived from the V3-variable loop of gp120 (REF. 31). This

\section{Box 1 | Defining nanotechnology}

Definitions of the exact size range that the field of nanotechnology covers have been determined on the basis of size as well as function. The US National Nanotechnology Initiative aims to expedite the discovery, the development and the deployment of nanoscale technology for public benefit, and defines nanotechnology on the basis of size alone, using the range of 1 to $100 \mathrm{~nm}^{122}$. Other groups, including the US Food and Drug Administration (FDA), define nanotechnology on the basis of scale and function, using the range of 1 to $1,000 \mathrm{~nm}$, provided that the physical, chemical or biological effects of the material in question are attributable to its dimensions ${ }^{123}$. The European Medicines Agency (EMA) initially defined nanotechnology in the range of 0.2 to $100 \mathrm{~nm}$ in size but has broadened the definition to less than $1,000 \mathrm{~nm}$ in size ${ }^{124}$. engineered epitope was designed by modelling the stable three-dimensional $\beta$-hairpin conformation that is formed after the binding of a broadly cross-neutralizing human monoclonal antibody to the gp120 antigen. This synthetic VLP also incorporated a universal $\mathrm{T}_{\mathrm{H}}$ cell epitope ${ }^{32}$ (this immunogenic peptide promiscuously binds to multiple different MHC class II molecules to improve the induction of $\mathrm{T}_{\mathrm{H}}$ cells) and a tripalmitoyl-S-glyceryl cysteine (Pam3Cys) lipid moiety, which induces TLR2 activation. Interestingly, the immunization of New Zealand white rabbits with these synthetic VLPs alone induced the production of neutralizing antibodies against the envelope proteins of multiple HIV-1 strains ${ }^{31}$. Thus, structural vaccinology and other strategies for immunogen design ${ }^{29,33}$, in combination with repetitive antigen display using nanoparticle-based technologies as a vaccine platform, might enable the induction of responses against poorly accessible but conserved neutralizing epitopes rather than against more readily accessible immunodominant non-neutralizing epitopes expressed on the native gp120 spike ${ }^{29}$. Responses against these poorly accessible epitopes are required to overcome the extraordinary mutation rate and the diversification of HIV-1 during the course of infection and to prevent viral escape.

The design of synthetic nanoparticles to incorporate lipid moieties for the conformational stabilization of protein antigens, such as the membrane-proximal external region of gp41, is also of great interest as certain 
a Delivery of antigens

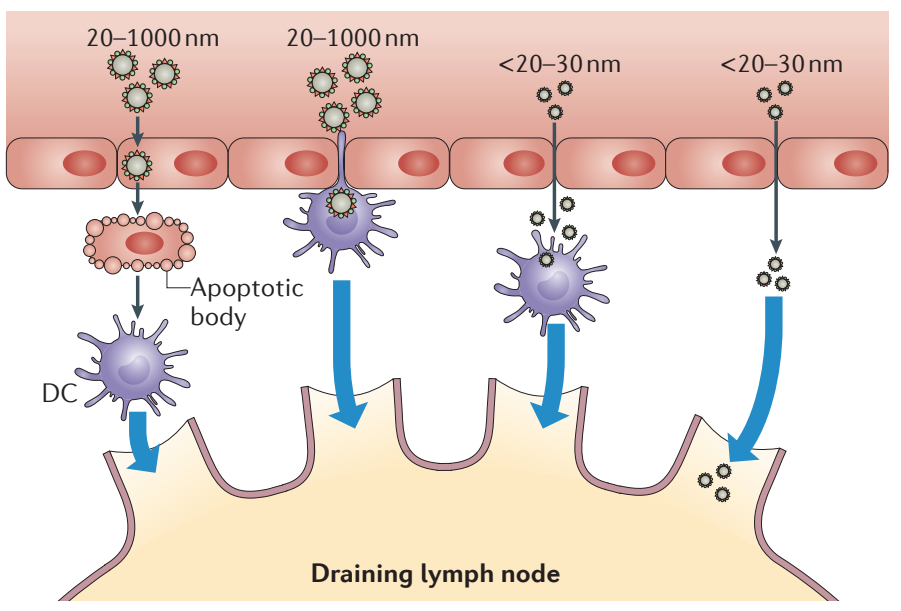

c Repetitive antigen display

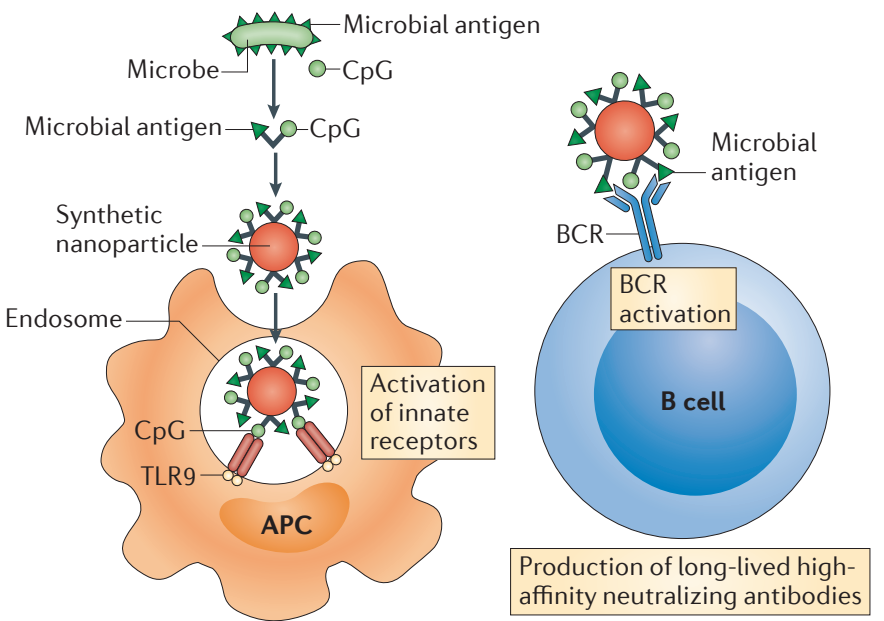

b Depot effect

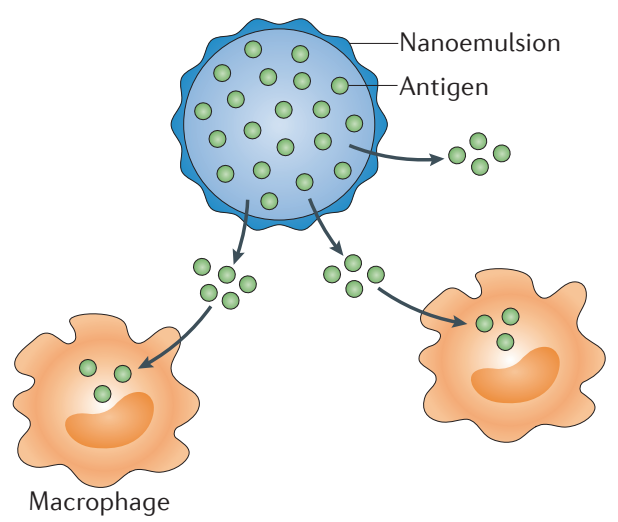

d Cross-presentation

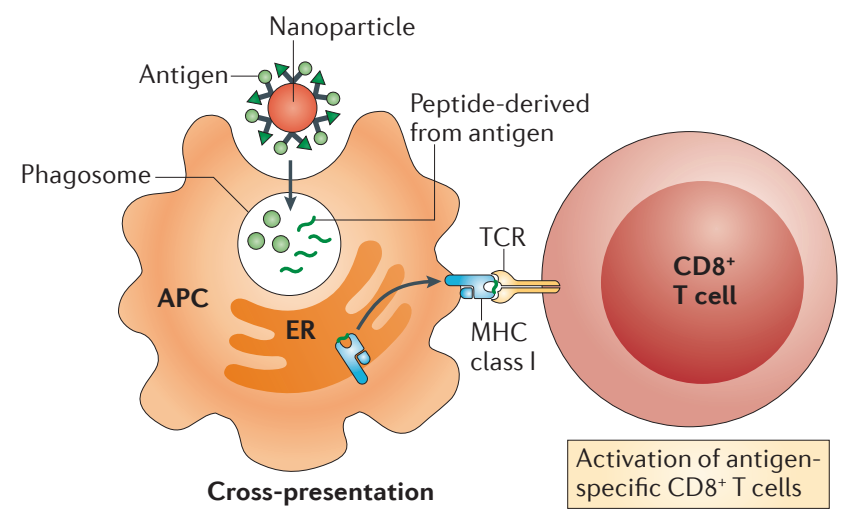

Figure 2 | Mechanisms by which nanoparticles alter the induction of immune responses. The immunostimulatory activity of nanoscale materials has been attributed to diverse mechanisms: the delivery of antigens, including particle size-dependent tissue penetration and access to the lymphatics (part a); a depot effect, which promotes the persistence, the stability, the conformational integrity and the gradual release of vaccine antigens (part b); and repetitive antigen display in which the spatial organization of the antigens on the particle surface facilitates $B$ cell receptor (BCR) co-aggregation, triggering and activation (part c). Additional mechanisms associated with innate immune potentiation include Toll-like receptor (TLR)-dependent and TLR-independent signal transduction (not shown); cross-presentation, which is a mechanism by which exogenously acquired-antigens are processed into MHC class I pathways, caused by the nanoparticle-mediated leakage of antigens into the cytosol after they have been taken up by the phagosome (part $\mathbf{d}$ ); and the release of soluble mediators such as cytokines, chemokines and immunomodulatory molecules that regulate the immune response (not shown). APC, antigen-presenting cell; DC, dendritic cell; ER, endoplasmic reticulum; TCR, T cell receptor.

broadly reactive HIV-1-neutralizing antibodies that interfere with Env-mediated viral membrane fusion have been shown to engage with both membrane lipid and protein components ${ }^{34,35}$ that contribute to native antigenic structure. These interactions potentially enable the generation of improved protective immune responses to the vaccine. Finally, new design strategies for nanoparticle-based vaccines are needed to focus immune responses against conserved CTL epitopes, as cell-mediated immune responses, together with broadly neutralizing antibodies, are associated with the initial control of HIV-1 infection and other viral diseases $^{36}$.
Nanoparticle-based vaccine carriers. Several different types of nanoparticles have been used either alone as vaccine carriers to entrap antigens or together with other agents, such as humanized DC-specific antibodies ${ }^{10}$ or immunomodulators, to enable targeted antigen delivery and the activation of APCs ${ }^{37}$. Examples of nanoparticles that have been used as vaccine carriers include biodegradable poly(lactide-co-glycolide) (PLGA) nanoparticles, co-polymer hydrogels or 'nanogels', cholesterol-bearing hydrophobized pullulan (CHP) and cationic liposomes. Polymers have been used in nanotechnology as nanoparticles, nanospheres and nanocapsules. Vaccine carriers composed of PLGA 


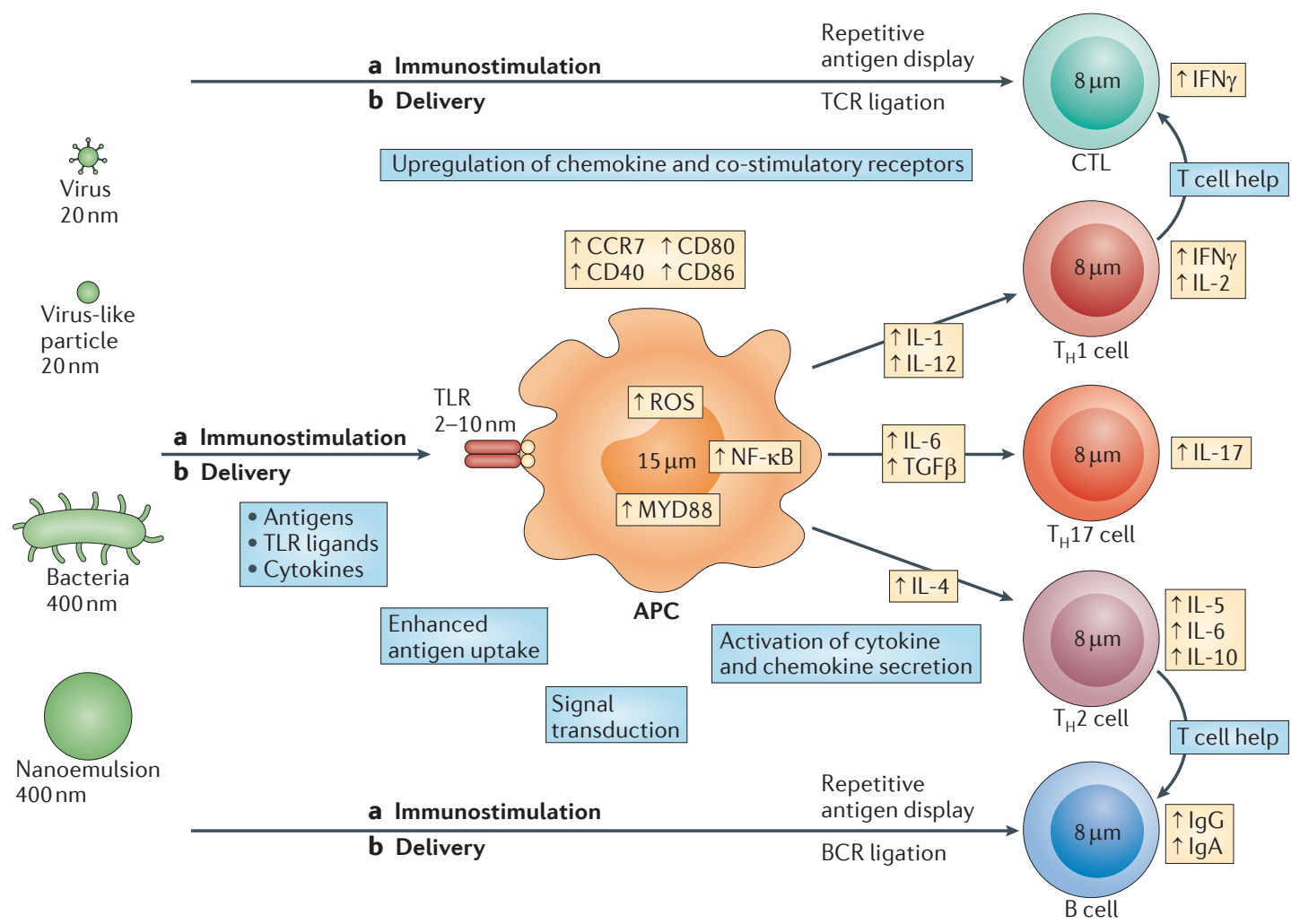

Figure 3 | Nanoscale immune activation. Nanoscale products might have a direct immunostimulatory effect (part a) on components of the immune system, including antigen presenting cells (APCs), B cells or T cells; they might deliver compounds that result in immunostimulation (part b); or they might use both mechanisms at the same time. Direct effects include the upregulation of homing receptors such as CC-chemokine receptor 7 (CCR7) and co-stimulatory molecules including CD40, CD80 and CD86, which results in the enhanced secretion of cytokines and increased B cell and T cell activation. Enhanced delivery of antigens and adjuvants might result in apoptosis or necrosis, which enhances vaccine immunogenicity. The pathways shown are representative examples of how different nanoparticles might activate the immune system. BCR, B cell receptor; CTL, cytotoxic T cell; IFN $\gamma$, interferon- $\gamma$; IL, interleukin; MYD88, myeloid differentiation primary-response protein 88 ; NF- $\mathrm{kB}$, nuclear factor- $\mathrm{B}$; ROS, reactive oxygen species; TCR, T cell receptor; TGF $\beta$, transforming growth factor- $\beta ; T_{H}$, T helper; TLR, Toll-like receptor.

have been extensively characterized in animal models and are widely used in clinical applications as a matrix to encapsulate, co-deliver and gradually release active drugs $^{38}$. In vaccine development, pegylated PLGA (150$200 \mathrm{~nm}$ in size) has been used to encapsulate hepatitis B surface antigen ( $\mathrm{HBsAg}$ ), and it promotes the rapid uptake and the endosomal localization of vaccine antigens in DCs, as well as the subsequent production of high titres of antigen-specific antibodies ${ }^{39}$.

A thermosensitive biodegradable hydrogel consisting of the monomethoxy form of pegylated PLGA (less than $100 \mathrm{~nm}$ in size) has recently been used in mice to achieve the subcutaneous delivery of HBsAg at the injection site at the same time as the local and sustained release of granulocyte/macrophage colony-stimulating factor (GM-CSF), which is a crucial cytokine for the survival, the differentiation and the maturation of $\mathrm{DCs}^{40}$. This vaccine enhanced the recruitment of DC precursor cells to the site of injection and promoted the maturation and the migration of CD11 $\mathrm{c}^{+} \mathrm{DCs}$ to the local draining lymph nodes. This was followed by the strong induction of HBsAg-specific antibody and T cell responses, even in mice that do not normally generate immune responses against HBsAg or when low concentrations $(\leq 2 \mu \mathrm{g})$ of HBsAg were used. Importantly, this suggests that this adjuvant could potentially be used in vaccines that incorporate poorly immunogenic antigens or in vaccines for individuals who have an impaired immune system. The ability to protect antigens or other bioactive mediators, to maintain the native conformation of these components at the site of immune challenge and to create a depot effect with the gradual local release of antigens over time is a key advantage for these types of nanoparticles. Biodegradable nanoparticles have also been shown to be safe and biocompatible for use in vaccine technology ${ }^{38}$.

SAPNs. The unique properties of certain microbial pathogens and VLPs have inspired and guided the systematic modelling, design and manufacture of novel nanoparticles that use combinations of both naturally occurring and synthetically engineered biostructural motifs to optimize immune responses to vaccine antigens. SAPNs constructed from different protein oligomerization domains have been designed to achieve repetitive antigen display ${ }^{41}$ (FIG. 2). A customized recombinant 


\section{Table 2 | Examples of immunostimulatory nanovaccines}

\begin{tabular}{|c|c|c|c|c|c|}
\hline Compound & Size & Medical application & Mechanism & Current use & Refs \\
\hline Virus-like particles & $15-30 \mathrm{~nm}$ & $\begin{array}{l}\text { Vaccine carrier and } \\
\text { adjuvant }\end{array}$ & $\begin{array}{l}\text { Repetitive antigen display, structural } \\
\text { or molecular mimicry of virus, particle } \\
\text { size-dependent tissue penetration and } \\
\text { trafficking to lymphatics, and TLR activation }\end{array}$ & $\begin{array}{l}\text { In humans and } \\
\text { animals }\end{array}$ & $\begin{array}{r}4,5,14,15 \\
18,32\end{array}$ \\
\hline $\begin{array}{l}\text { MF59 (squalene } \\
\text { oil-in-water } \\
\text { emulsion) }\end{array}$ & $165 \mathrm{~nm}$ & Vaccine adjuvant & $\begin{array}{l}\text { Neutrophil, monocyte and } \mathrm{DC} \text { recruitment, } \\
\text { antigen uptake, and the induction of } \\
\text { humoral and } \mathrm{T}_{\mathrm{H}} 1 \text {-type immune responses }\end{array}$ & In humans & 48 \\
\hline $\begin{array}{l}\text { Poly(lactide- } \\
\text { co-glycolide) } \\
\text { nanoparticles }\end{array}$ & $100-200 \mathrm{~nm}$ & $\begin{array}{l}\text { Vaccine carrier } \\
\text { and adjuvant } \\
\text { when combined } \\
\text { with bioactive } \\
\text { immunomodulators }\end{array}$ & $\begin{array}{l}\text { Encapsulation for sustained local antigens } \\
\text { and co-mediator release }\end{array}$ & In mice & 139,140 \\
\hline Cationic liposomes & $200-1,000 \mathrm{~nm}$ & Vaccine carrier & $\begin{array}{l}\text { Encapsulation and targeted antigen } \\
\text { delivery or uptake by APCs, and } \\
\text { recruitment of monocytes to the injection } \\
\text { site }\end{array}$ & $\begin{array}{l}\text { In humans and } \\
\text { mice }\end{array}$ & $\begin{array}{r}74,75 \\
76,146\end{array}$ \\
\hline $\begin{array}{l}\text { Immune-stimulating } \\
\text { complexes }\end{array}$ & $40 \mathrm{~nm}$ & $\begin{array}{l}\text { Vaccine carrier and } \\
\text { adjuvant }\end{array}$ & $\begin{array}{l}\text { Targeting, antigen uptake and activation } \\
\text { of DCs }\end{array}$ & $\begin{array}{l}\text { In humans and } \\
\text { mice }\end{array}$ & 147,148 \\
\hline
\end{tabular}

APC, antigen-presenting cell; DC, dendritic cell; $\mathrm{T}_{\mathrm{H}}$, T helper; TLR, Toll-like receptor.

construct, which is expressed in Escherichia coli, encodes a single polypeptide chain with two different linked protein oligomerization domains, each containing particular coiled-coil heptad repeat patterns that drive the self assembly of the purified monomers into nanoparticles approximately 16 to $25 \mathrm{~nm}$ in diameter; these nanoparticles have icosahedral symmetry that is analogous to viral capsids. Thus, SAPNs provide a repeating scaffold structure to enable the conformational presentation of inserted protein epitopes or domains in a highly exposed configuration that protrudes or extends from the surface of the particle after the assembly of the subunits ${ }^{41}$. Approximately 180 peptide chains are assembled into a single nanoparticle to form this icosahedral structure. This geometry enables the manipulation of nearly all of the parameters described above as being necessary for VLPs: a scaffold for antigen display and cellular activation that leads to substantial increases in the specific production of high-titre, high-affinity antibodies directed against the inserted linear or conformational antigen epitopes $^{42}$.

SAPNs have been produced with the insertion of a range of different antigens, including the hydrophobic loop-peptide epitope of actin, and can successfully induce the production of antibodies against poorly antigenic phylogenetically conserved determinants ${ }^{43}$. The incorporation of trimeric coiled-coil epitopes from the surface protein of severe acute respiratory syndrome coronavirus (SARS-CoV) into SAPNs was shown to strongly induce the production of virus-specific neutralizing antibodies after the immunization of mice with these SAPNs ${ }^{44}$. In addition, the insertion of a tetrameric form of the immunogenic epitope from the external domain of the avian influenza virus matrix protein 2 (M2e) into SAPNs led to the high-density display of oligomeric epitopes in a native conformation and the subsequent reduction of $\mathrm{H} 5 \mathrm{~N} 2$ virus-shedding after the immunization of chickens with these SAPNs ${ }^{45}$. Furthermore, the integration of a tandem repeat of an immunodominant B cell epitope from the malaria parasite Plasmodium berghei circumsporozoite protein (CSP) into SAPNs induced the production of T cell-dependent high-avidity antibodies in mice without the use of an adjuvant. This protected mice against both primary and long-term secondary challenges with live sporozoites without causing parasitaemia ${ }^{46}$. Interestingly, modification of the SAPN vaccine to incorporate both B cell and $\mathrm{T}$ cell epitopes derived from the CSP of the human malaria parasite Plasmodium falciparum induced the production of both high-titre antibodies and longlived polyfunctional interferon- $\gamma($ IFN $\gamma)$-producing central memory $\mathrm{T}$ cells, which protected mice against a lethal dose of a transgenic $P$. berghei malaria parasite that expressed the CSP from P. falciparum ${ }^{14}$. Finally, the a-helical domain located in the membrane-proximal external region of HIV-1 gp41 was incorporated into a SAPN scaffold to recapitulate the epitopes recognized by pre-existing HIV-1-neutralizing antibodies; however, this approach was unsuccessful in inducing HIV-1-neutralizing antibodies in immunized rats ${ }^{47}$. 
Nanoemulsions. Nanoemulsion adjuvants are oil-in-water emulsions that are composed of solvents and surfactants. An example of a nanoemulsion is MF59, which consists of squalene oil in combination with polysorbate 80 (Tween 80 ) and sorbitan trioleate (Span 85). MF59 has been licensed in Europe as a clinical vaccine adjuvant for influenza and has been intramuscularly administered to tens of millions of healthy adults, elderly individuals and children ${ }^{48}$. The adjuvant activity seems to involve a combination of mechanisms, including an increased cellular uptake of antigens, an enhanced release of cytokines and chemokines, a recruitment of monocytes and granulocytes to the site of intramuscular injection, and an augmented maturation and upregulation of CC-chemokine receptor 7 (CCR7) by antigen-primed DCs, which promotes their migration to the draining lymph nodes ${ }^{49,50}$.

MF59 has been shown to be a more potent adjuvant than alum for inducing broadly protective humoral and $\mathrm{T}_{\mathrm{H}} 1$-type cell-mediated immune responses ${ }^{48,51,52}$. Furthermore, with respect to vaccination against pandemic influenza viruses (for example, H5N1), M59 promotes protective antiviral immune responses when delivered with relatively low doses of virus-derived antigens. By contrast, the delivery of similar antigen doses in combination with alum results in variable or ineffective antiviral immunity ${ }^{48,53}$. The clinical experience of using MF59 has been documented in these clinical studies as well as in post-marketing surveillance. Increased reactogenicity, including injection site pain, has been described following administration of MF59 and has been attributed to the increased inflammation that is associated with the enhanced immune response. The ratio of the increased reactogenicity to the benefit of increased immunity remains favourable, especially if enhanced responses are needed, as is the case with pandemic influenza vaccines ${ }^{54}$. Early-stage clinical trials are currently in progress to study the efficacy of MF59 as an adjuvant for vaccines against other viral pathogens, including herpes simplex virus, $\mathrm{HBV}$ and cytomegalovirus ${ }^{48}$. Intranasal administration of MF59 enhanced serum antibody responses in naive mice but not in pre-infected mice ${ }^{55}$ or in humans ${ }^{56}$.

The nanoemulsion $\mathrm{W}_{80} 5 \mathrm{EC}$ is composed of soybean oil as opposed to squalene and has been shown, both in animal models and more recently in humans, to augment the targeting of vaccine antigens to the immune system and to safely induce potent mucosal, humoral and cellular immune responses after its intranasal administration ${ }^{57}$. The adjuvant activity of this nanoemulsion-antigen mixture is primarily dependent on the retention of a nanodroplet structure in the emulsion and on the positive charge that facilitates binding to negatively charged proteins such as mucin. The nanoscale size and positive $\zeta$-potential of the emulsion enables the penetration of the mucous layer, the binding to cell membranes and the cellular uptake that together mediate the induction of the innate and the adaptive immune responses ${ }^{58}$. Cytokine secretion by ciliated epithelial cells in the nasal mucosa and by cells in the nasal-associated lymphoid tissues (NALT) is followed by the activation and the migration of antigen-primed DEC205 (also known as LY75)+ DCs to the regional lymph nodes ${ }^{59}$. Interestingly, nanoemulsions have been shown to induce necrosis or apoptosis in epithelial cells and to simultaneously activate the surface expression of calreticulin, which is a signal for immunogenic cell death ${ }^{60,61}$. These observations are consistent with a mechanism by which nanoemulsions rapidly facilitate the engulfment of dying antigenloaded epithelial cells by DCs and other phagocytic cells in the tissue ${ }^{59}$. Nanoemulsions have broad antimicrobial activity against enveloped viruses, bacteria and fungi ${ }^{62-65}$ and can be used to inactivate, as well as to provide adjuvant activity, for vaccine preparations involving intact viruses such as vaccinia virus ${ }^{66}$, respiratory syncytial virus (RSV) ${ }^{67}$ and influenza viruses ${ }^{68}$. Single-antigen formulations, including the $17 \mathrm{kDa}$ outer membrane lipid protein A (OmpA) polypeptide from Burkholderia cenocepacia ${ }^{69}$, the anthrax protective antigen $^{70}$, the HIV-1 envelope protein gp120 (REF. 71) and the hepatitis B surface antigen ${ }^{58}$, can also be used as adjuvants.

Nanoemulsions have shown little or no toxicity during extensive testing in multiple species ${ }^{58,66,70,71}$ and no serious adverse effects in humans, although intranasally administered nanoemulsions have only been evaluated in less than 200 individuals so far $^{57}$. This is particularly relevant as the history of intranasally administered adjuvants includes an association of cranial nerve VII palsy (also known as Bell's palsy) with the nasal administration of influenza virosomes together with the E. coli heat labile toxin mucosal adjuvant ${ }^{72}$. Although there is no evidence that an intranasally administered nanoemulsion adjuvant undergoes retrograde transport or that it is associated with cranial nerve VII palsy, vigilant monitoring for this side effect and others will continue throughout the clinical development programme and after it has been licensed.

Cationic liposomes. Cationic liposomes (typically ranging in particle diameter from 200 to $1,000 \mathrm{~nm}$ depending on the formulation) have been used as vaccine adjuvants and delivery systems to encapsulate, protect and enable antigen uptake with the prolonged activation of professional APCs ${ }^{73,74}$. The cationic charge and the composition of the lipid components is essential for efficient antigen adsorption to the nanoparticle during the preparation of the vaccine, for retention at the site of injection, for innate activation of immune accessory cells and for vaccine immunogenicity, including the induction of $\mathrm{T}_{\mathrm{H}} 1$-type cellular responses ${ }^{75,76,77,74}$. Different cationic lipids incorporated into these formulations have included quaternary ammonium compounds (for example, dimethyl dioctadecyl ammonium bromide (DDA) and 1,2-dioleoyl-3-trimethyl-ammoniumpropane (DOTAP)), cholesterol derivatives (for example, dimethylaminoethanecarbamoyl-cholesterol), imidazolium compounds (for example, 1-[2-(oleoyloxy)ethyl]-2-oleyl-3-(2-hydroxyethyl)imidazolinium chloride (DOTIM)), diC14-amidine-based compounds and other immunostimulants such as trehalose 
a Direct immunosuppressive effect

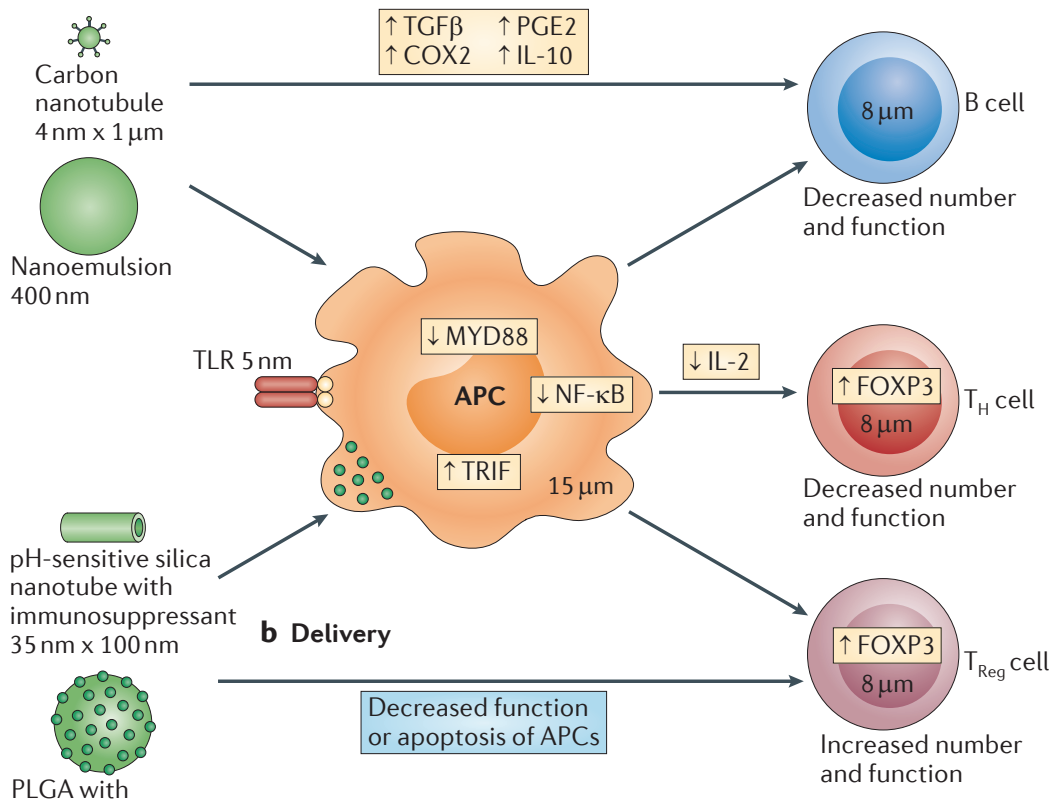

immunosuppressant $400 \mathrm{~nm}$

Figure 4 | Nanoscale immunosuppression. Nanoscale products might have a direct immunosuppressive effect (part a) on components of the immune response, including antigen presenting cells (APCs), B cells or T cells; they might deliver compounds that result in immunosuppression (part b); or they might use both mechanisms at the same time. Direct effects include the upregulation of transforming growth factor- $\beta$ (TGF $\beta$ ), which results in increased cyclooxygenase 2 (COX2), prostangandin E2 (PGE2) and interleukin-10 (IL-10), and decreased B cell and T cell activity, as well as apoptosis. The delivery of immunosuppressants results in a decreased response to IL-2 with sirolimus, the downregulation of nuclear factor- $\mathrm{KB}(\mathrm{NF}-\mathrm{\kappa B})$ with steroids and the upregulation of forkhead box P3 (FOXP3), which results in increased regulatory $T$ cell ( $T_{\text {Reg }}$ ) activity when self antigens are presented in a nanoemulsion. The pathways shown are representative examples by which different nanoscale products might suppress the immune system. MYD88, myeloid differentiation primary-response protein 88; PLGA, poly(lactideco-glycolide); $\mathrm{T}_{\mathrm{H}}$, T helper; TLR, Toll-like receptor; TRIF, TIR-domain-containing adaptor protein inducing IFN $\beta$. and they induce the development of IgG and IgA antibodies, both systemically and locally, depending on the formulation and the route of delivery (FIG. 2). These studies indicate that different nanoparticle compositions can be engineered as desired to enhance the immune response through mechanisms associated with nanoparticle delivery, the controlled release of antigens or the entrapment of immunomodulators in the same location, in addition to the recruitment, the targeting and the uptake of antigens by accessory cells and professional APCs (TABLE 2).

\section{Nanotechnology and immunosuppression}

In addition to stimulating and directing the immune response, nanotechnology can be therapeutically used to inhibit the detrimental immune responses that occur in allergy, autoimmunity and in transplant rejection. The immunosuppressive effects of nanotherapeutics are discussed in the following sections (FIG. 4; TABLE 3).

Immunosuppressive effects of fullerenes. Much of the work exploring the direct effect of nanoparticles on the immune response has come from the field of toxicology, in which fullerenes have been shown to have direct immunosuppressive effects ${ }^{83}$. Fullerenes are molecules that are exclusively composed of carbon and that are commonly used in nanotechnology in the development of items such as electronics, paints and polymer composites $^{84}$. Fullerenes are globally produced in the order of hundreds of tonnes per year ${ }^{85}$. Spherical fullerenes are approximately $1 \mathrm{~nm}$ in diameter and can absorb electrons through the benzene rings on their surface, which enables them to function as scavengers for reactive oxygen species (ROS $)^{86}$. When incubated with human mast cells and peripheral blood basophils, spherical fullerenes result in decreased IgE receptor-mediated signalling, decreased production of ROS and decreased degranulation. In a mouse model of anaphylaxis, fullerene treatment prevents histamine release and prevents the reduction in body temperature that normally occurs in mice after allergen challenge ${ }^{87}$.

When fullerene-like structures are manufactured as cylinders they are called carbon nanotubules (CNTs) and they typically have a diameter of approximately $10 \mathrm{~nm}$ and a length that can be as much as several micrometres. These structures can be formed as singlewalled or multi-walled tubes, both of which have been shown to have direct immunosuppressive effects. Mice exposed to single-walled CNTs by pharyngeal aspiration had increased levels of inflammation in the lungs and enhanced recruitment of DCs, alveolar macrophages, polymorphonuclear cells and lymphocytes. Interestingly, when cultured with stimulatory DCs, both the proliferation and the expansion of splenic $T$ cell populations were decreased in animals that had been exposed to single-walled CNTs. In co-culture experiments, DCs that had been exposed to both lipopolysaccharide (LPS) and single-walled CNTs were less capable of promoting the proliferation and the expansion of $\mathrm{T}$ cell populations than DCs that had been exposed to LPS alone ${ }^{88}$. 


\begin{tabular}{|c|c|c|c|c|c|}
\hline Compound & Size & Medical application & Mechanism & Current use & Refs \\
\hline \multicolumn{6}{|l|}{ Direct } \\
\hline $\begin{array}{l}\text { Single-walled carbon } \\
\text { nanotubules }\end{array}$ & $\begin{array}{l}\text { 1-4 nm diameter; } \\
1,000-3,000 \mathrm{~nm} \text { length }\end{array}$ & Inhalation exposure & Suppression of DC function & In mice & 88 \\
\hline \multicolumn{6}{|l|}{ Delivery } \\
\hline Nanocrystals & $200 \mathrm{~nm}$ & Transplant rejection & Sirolimus & Licensed in humans & 92,93 \\
\hline $\begin{array}{l}\text { Polyamidoamine } \\
\text { dendrimers }\end{array}$ & $1-20 \mathrm{~nm}$ & $\begin{array}{l}\text { Cerebral palsy, } \\
\text { scar formation and } \\
\text { gastroenteritis }\end{array}$ & $\mathrm{N}$-acetyl- cysteine glycosamine & In rabbits & $\begin{array}{r}92,95 \\
96,98\end{array}$ \\
\hline Carbon nanotubules & $\begin{array}{l}3.5 \mathrm{~nm} \text { diameter and } \\
90 \mathrm{~nm} \text { length }\end{array}$ & Induction of apoptosis & $\begin{array}{l}\text { Cytochrome } c \text { and } \\
\text { phosphatidylserine }\end{array}$ & In mice and rats & $\begin{array}{r}91,106 \\
111,149\end{array}$ \\
\hline $\begin{array}{l}\text { Solid lipid } \\
\text { nanoparticles }\end{array}$ & $200-400 \mathrm{~nm}$ & Transplant rejection & Cyclosporin & In humans & $\begin{array}{r}92, \\
112,113\end{array}$ \\
\hline Liposomes & $100-160 \mathrm{~nm}$ & $\begin{array}{l}\text { Arthritis, coronary } \\
\text { artery stenosis and } \\
\text { acute lung injury }\end{array}$ & Liposomal bisphosphanates & $\begin{array}{l}\text { In rats, rabbits and } \\
\text { pigs }\end{array}$ & $\begin{array}{r}95, \\
108-110\end{array}$ \\
\hline $\begin{array}{l}\text { Liposomes with } \\
\text { DC-targeting ligands }\end{array}$ & $50-92 \mathrm{~nm}$ & Autoimmune disease & siRNA & In mice & $\begin{array}{r}100-102 \\
106,111\end{array}$ \\
\hline $\begin{array}{l}\text { Sterically stabilized } \\
\text { phospholipid micelles }\end{array}$ & $15 \mathrm{~nm}$ & Rheumatoid arthritis & $\begin{array}{l}\text { Camptothecin and vasoactive } \\
\text { intestinal peptide }\end{array}$ & In mice & $\begin{array}{r}91,112 \\
113,149\end{array}$ \\
\hline
\end{tabular}

Although the mechanisms responsible for the effect of single-walled CNTs on DC function have not been fully elucidated, more is known about the mechanisms by which multi-walled CNTs affect T cell function. Animals exposed to inhaled multi-walled CNTs for several weeks showed no increase in pulmonary inflammation but they showed systemic immune suppression in the form of decreased $\mathrm{T}$ cell proliferation and a lower production of $\mathrm{T}$ cell-dependent antibod$\mathrm{ies}^{85}$. The gene expression of the enzymes cyclooxygenase 2 (COX2; also known as PTGS2) and prostaglandin E synthase 2 (PTGES2) was upregulated in the spleens of multi-walled CNT-treated mice - a response that was abrogated by the administration of a cyclooxygenase 1 (COX1) antagonist and in COX2-knockout mice. The overall immunosuppressive effect was shown to be mediated by transforming growth factor- $\beta$ (TGF $\beta$ ) produced by alveolar macrophages ${ }^{89}$.

Fullerenes, which have direct immunosuppressive effects (discussed above), also have the capacity to store and to deliver active drug substances that have immunosuppressive properties. Although spherical fullerenes have not been efficient in the delivery of immunosuppressive drugs such as dexamethasone ${ }^{90}$, carbon nanotubules have been used to effectively deliver compounds such as the pro-apoptotic protein cytochrome $c^{91}$.
Nanoparticles as vehicles for immunosuppressants. In addition to having direct immunosuppressive effects, nanotechnology can also be used to deliver drugs with known immunosuppressive activity; for example, nanocrystals are used to increase the water solubility and the bioavailability of immunosuppressive drugs that are used to prevent transplant rejection, such as sirolimus ${ }^{92,93}$. Sirolimus is a triene macrolide that has immunosuppressive effects through the inhibition of IL-2 and other proinflammatory cytokines. Owing to its poor solubility in water, the initial formulations of sirolimus were oral solutions with solvent-water mixtures. The currently licensed oral tablet formulation was made available by the use of nanometre-sized crystals generated using nanoscale stabilizers $^{93}$.

Dendrimers and polymers. Dendrimers are molecules that repetitively branch around a focal point. Similarly to nanocrystals, dendrimers can encapsulate active drugs and in this way they can deliver active drugs to target tissues. In addition, dendrimers and polymers can present targeting ligands ${ }^{94}$. Polyamidoamine (PAMAM) dendrimers are among the best known dendrimers and are composed of a diamine core reacted with methyl acrylate, followed by another diamine, which results in regular radially concentric layers or 'generations' that give rise to successively larger dendrimers. PAMAM dendrimers have 
been reported to deliver $N$-acetyl cysteine (NAC) across the blood brain barrier. NAC is an antioxidant and an anti-inflammatory agent that is commonly used to treat acetaminophen poisoning and as a mucolytic. On the basis of work showing PAMAM dendrimers to localize to activated microglia and astrocytes in rabbits with cerebral palsy, NAC has been conjugated to a PAMAM dendrimer and intravenously administered to rabbits with cerebral palsy. The administration of NAC with a PAMAM dendrimer but not NAC alone was reported to decrease neuroinflammation and to improve motor function ${ }^{95}$.

Other examples of the use of PAMAM dendrimers in immunosuppression include the development of PAMAM dendrimer glucosamines that have been shown to inhibit TLR4-mediated inflammatory responses and scar tissue formation ${ }^{96}$. Mechanistic studies have shown that the PAMAM dendrimer glucosamine blocks the formation of the TLR4-MD2 (also known as LY96)-LPS complex ${ }^{97}$ by interfering with the electrostatic binding of LPS to MD2 and by blocking the entry of the lipid chains of LPS into the hydrophobic pocket of MD2. On the basis of these findings, the dendrimer glucosamine has been tested in the rabbit ileal loop model of Shigella spp. infection and has been shown to decrease IL-6 and IL-8 production ${ }^{98}$ and, as a proof of concept, to decrease inflammation in this model of gastroenteritis.

The effects of dendrimers on TLR7 and TLR8 have also been studied using a dendrimer synthesized from the TLR7 and TLR8 agonist imidazoquinoline ${ }^{99}$. Interestingly, dendrimerization of the small molecule imidazoquinoline ${ }^{99}$ results in a loss of TLR8 activity and a maintenance of TLR7 activity, with an initial dosedependent increase in cytokine production followed by a decrease. Although the mechanisms by which particular TLRs are 'turned on' and 'turned off' by dendrimers is not fully understood, it highlights the possibility of molecular manipulation at the nanoscale level with respect to both elucidating and modulating the innate immune response for therapeutic use.

PLGA has been formulated at the nanoscale level and has been used to deliver immunosuppressants including betamethasone ${ }^{100}$, bifunctional peptide inhibitors and leukaemia-inhibitory factor (LIF) ${ }^{101}$. The addition of betamethasone to PLGA resulted in a more sustained anti-inflammatory effect in two animal models of arthritis compared with betamethasone alone ${ }^{100}$. Bifunctional peptide inhibitors that simultaneously target MHC class II molecules and intercellular adhesion molecule 1 (ICAM1) have been effectively delivered using PLGA complexes, which results in decreased cytokine production and a suppression of disease in mice with experimental autoimmune encephalomyelitis ${ }^{101}$. PLGA has also been used to deliver LIF, which results in the upregulation of forkhead box P3 (FOXP3) expression by $\mathrm{T}$ cells and an expansion of the regulatory $\mathrm{T}$ cell population in mice. This effect was not seen when LIF was administered to mice in the absence of PLGA ${ }^{102}$.

The type of polymer and the route of administration might also influence whether there is an enhanced or a suppressed immune response. When negatively charged PLGA was compared to positively charged $\mathrm{N}$-trimethyl chitosan (TMC) both nanoparticles increased the humoral immune responses to ovalbumin when intramuscularly administered; however, only the negatively charged TMC increased the humoral immune responses to ovalbumin when intranasally administered ${ }^{103}$. This is probably due to the electrostatic interaction of the positively charged carrier and the negatively charged mucous and has been shown to occur with other carriers, including liposomes ${ }^{104}$ and nanoemulsions. Interestingly, only the negatively charged intranasally administered PLGA induced immunoregulatory responses, which were characterized by enhanced FOXP3 expression in NALT and cervical lymph nodes, by decreased delayed type hypersensitivity responses and by increased IL-10 expres$\operatorname{sion}^{105}$. These results show that the type of polymer, its charge and the route of administration can influence whether the resultant immune response is enhanced or suppressed ${ }^{105}$.

SLNs, liposomes and micelles. Lipid-based nanotechnology includes solid lipid nanoparticles (SLNs), liposomes and micelles (FIG. 1). SLNs are solid at room temperature and body temperature, whereas liposomes and micelles are liquid at these temperatures. Liposomes are vesicles composed of a lipid bilayer with a hydrophilic centre. Conversely, micelles are composed of amphiphilic molecules arranged as oil in water (a hydrophobic core) or water in oil (a hydrophilic core). An active drug is incorporated and delivered by the carrier, which is chosen on the basis of composition, size and charge ${ }^{92,106}$. In addition, the carrier might be targeted to specific tissues using specific ligands ${ }^{107}$. Examples of liposomes that have been used as carriers to achieve immunosuppression include bisphosphonates, such as clondronate, to deplete pulmonary macrophages in acute lung injury ${ }^{108}$ and arthritis ${ }^{109}$, as well as alendronate to deplete circulating monocytes in coronary artery stenosis ${ }^{110}$. Targeting of liposomes to specific cells is exemplified by the delivery of small interfering RNAs (siRNAs) to DCs by surrounding the liposome that is carrying the siRNA with a monoclonal antibody that is specific to DCs. This gene-silencing approach was used to specifically target CD40 expression by DCs and resulted in reduced levels of T cell proliferation in the liposome-treated mice ${ }^{111}$. Micelles have also been used to deliver agents that impair the immune response, including camptothecin ${ }^{112,113}$. Camptothecin is a topoisomerase inhibitor that was originally used in the treatment of cancer and has more recently been applied to the treatment of rheumatoid arthritis. The formulation of camptothecin in sterically stabilized micelles (SSMs) improved its delivery and had anti-inflammatory effects in a mouse model of arthritis; in this study, vasoactive intestinal peptide was used to target the SSMs to T cells, macrophages and synoviocytes ${ }^{112}$.

Nanoemulsions and immunosuppression. A final example of how nanotechnology can be applied to suppress an immune response is the use of nanoemulsions to deliver self antigens ${ }^{114}$. When the nanoemulsion $\mathrm{W}_{80} 5 \mathrm{EC}$ is combined with the self antigen thyroglobulin and is delivered to mice, the animals become tolerant to thyroglobulin; 
this response is characterized by a reduced humoral immune response to thyroglobulin, an upregulation of FOXP3 and TGF $\beta$ expression and increased T regulatory $\left(\mathrm{T}_{\mathrm{Reg}}\right)$ cell activity. This is particularly interesting, as $\mathrm{W}_{80} 5 \mathrm{EC}$ administered with foreign antigens enhances immune responses by increasing antigen delivery as well as by increasing TLR2 and TLR4 activation ${ }^{57,115}$. The signalling pathways that are activated after TLR4 stimulation include the myeloid differentiation primary-response gene 88 (MYD88) and the TIR domain-containing adaptor protein inducing interferon- $\beta$ (TRIF; also known as TICAM1) pathways, which result in the production and the release of pro-inflammatory cytokines ${ }^{116}$. As too much inflammation is detrimental to the host ${ }^{117}$, the control of TLR4 stimulation is an important immunoregulatory function. Endotoxin tolerance is a mechanism by which immunosuppression occurs in the continued presence of LPS ${ }^{118}$. In addition, the immunoregulatory molecule TGF $\beta$ has been described as being increased in endotoxin tolerance, as well as in the aforementioned direct immunosuppressive effects of fullerenes ${ }^{89}$ and in the indirect immunosuppressive effects of nanoemulsion delivery of self antigens ${ }^{114}$. Another similarity between the signalling mechanisms in nanotechnology-mediated immunosuppression and endotoxin tolerance is a relative increase in TRIF activation and a decrease in MYD88 activation $^{118}$. This 'TRIF bias' has been described for particular TLR4 agonists such as MPL ${ }^{119}$, which is an LPS derivative that is used as an adjuvant in numerous vaccines, including licensed recombinant HPV bivalent vaccine $^{120}$.

\section{Summary}

Nanotechnology is currently being used to engineer specific immune responses for prophylactic and therapeutic effects. In the future, the use of nanoparticles that have unique immunological properties determined by their size, shape, charge, porosity and hydrophobicity will enable researchers to 'customize' immune responses in new and unexpected ways. Improved protection against the outbreak of pandemic viruses and other emerging or mutating pathogens will require the rapid activation of innate and adaptive immune responses, ideally within hours (for an innate immune response) or days (for an adaptive immune response) after a single priming dose of vaccine. This could be achieved through the absorption of nanoparticles that have unique combinations of antigens and cytokines. It is also possible that passive immunity through nanoparticle-delivered immunoglobulin genes could produce antibodies specific for pathogens and could provide immune replacement rather than simply immune manipulation by nanotechnology.

In addition, the activation of CTL responses that can target tumours or virally infected cells can be accomplished in several ways using nanotechnology. Nanoparticles could be surrounded by antigens to augment CTL activity or they could be combined with immunomodulators, including cytokines such as GM-CSF, IL-12, IL-15 and FMS-related tyrosine kinase 3 ligand (FLT3L). As many co-stimulatory ligands are now known, multimerizing CD40 ligand (CD40L), glucocorticoid-induced TNFR-related protein (GITR; also known as TNFRSF18) or other activating and blocking ligands could turn lymphocytes on and off with greater precision than the antibodies that are currently being used to help to control autoimmunity and immune responses to allergens or even to transplanted organs. Using antigens with NOD-like receptors, TLR ligands and other microbial pattern recognition systems could induce CTL responses to antigens that normally do not produce this activity. It is also possible that 'suppressive nanoparticles' could be given to relatives of patients with specific autoimmune diseases in order to prevent disease development. Genetic screening for many immune diseases might enable the early correction of some immune defects using nanoparticle gene delivery methods rather than bone marrow transplantation.

In addition to the potential therapeutic applications of nanotechnology, recent advances in nanotechnologybased screening strategies using silicon nanowires in combination with siRNA and transcriptional profiling over time have shown promise for the selective perturbation of the immune response. This therefore has facilitated the identification of crucial points in the molecular network that regulates the immune response $\mathrm{e}^{121}$. These emerging nanotechnologies provide new ways to interrogate complex pathways that control the differentiation of immune cells, including the balance of $\mathrm{T}_{\mathrm{H}} 17$ and $\mathrm{T}_{\mathrm{Reg}}$ cells. This approach might also enable the future design of more effective therapeutics to regulate the immune system and to potentially reduce side effects and inflammation.

In summary, the field of nanotechnology will continue to provide remarkable insights into the nature of the immune response. The application of nanotechnology in immunology might also affect new strategies for the prevention or the treatment of human diseases.
1. Watson, J. D. \& Crick, F. H. Molecular structure of nucleic acids; a structure for deoxyribose nucleic acid Nature 171, 737-738 (1953).

2. Mandelkern, M., Elias, J. G., Eden, D. \&

Crothers, D. M. The dimensions of DNA in solution. J. Mol. Biol. 152, 153-161 (1981)

3. Jennings, G. T. \& Bachmann, M. F. Immunodrugs: therapeutic VLP-based vaccines for chronic diseases. Annu. Rev. Pharmacol. Toxicol. 49, 303-326 (2009).

4. Buonaguro, L., Tagliamonte, M., Tornesello, M. L. \& Buonaguro, F. M. Developments in virus-like particlebased vaccines for infectious diseases and cancer. Expert Rev. Vaccines 10, 1569-1583 (2011).

5. Goldinger, S. M. et al. Nano-particle vaccination combined with TLR-7 and -9 ligands triggers memory and effector CD8 ${ }^{+}$T-cell responses in melanoma patients. Eur. J. Immunol. 42, 3049-3061 (2012). This Phase Ila clinical trial shows both the advantages and the potential limitations of using an improved MelObG10 virus-like nanoparticle $(30 \mathrm{~nm})$ vaccine displaying MART1 on the surface together with integrated and exogenous TLR agonists for the enhanced generation of $T_{H} 1$ cell responses and effector or memory CD8 ${ }^{+} \mathrm{T}$ cell activation in late stage cancer patients.

6. Manolova, V. et al. Nanoparticles target distinct dendritic cell populations according to their size. Eur. J. Immunol. 38, 1404-1413 (2008).

This paper shows that polystyrene nanoparticles of a defined size $(20-200 \mathrm{~nm})$, or VLPs $(30 \mathrm{~nm})$ biodistribute rapidly to the draining lymph nodes to be taken up by lymph node resident DCs, whereas larger nanoparticles $(500-2,000 \mathrm{~nm})$ are acquired by DCs at the site of injection to be subsequently transported to the lymphatic tissues. This establishes nanoscale size as a crucial parameter for the mechanism of biodistribution and delivery and for vaccine applications. . Reddy, S. T. et al. Exploiting lymphatic transport and complement activation in nanoparticle vaccines. Nature Biotech. 25, 1159-1164 (2007).

This paper uses polyethylene glycol-stabilized polypropylene sulfide nanoparticles in the absence of specific targeting ligands to show efficient passive distribution of nanoparticles to the draining lymph nodes on the basis of size using differently sized particles of identical composition. 
8. Reddy, S. T., Rehor, A., Schmoekel, H. C. Hubbell, J. A. \& Swartz, M. A. In vivo targeting of dendritic cells in lymph nodes with poly(propylene sulfide) nanoparticles. J. Control Release 112, 26-34 (2006).

9. Fifis, T. et al. Size-dependent immunogenicity: therapeutic and protective properties of nano-vaccines against tumors. J. Immunol. 173, 3148-3154 (2004)

10. Cruz, L. J. et al. Targeted PLGA nano- but not microparticles specifically deliver antigen to human dendritic cells via DC-SIGN in vitro. J. Control Release 144, 118-126 (2010). This study shows a crucial contribution of nanoscale size to the uptake of targeted nanoparticles by DCs.

11. Paliard, X. et al. Priming of strong, broad, and longlived HIV type 1 p55 $5^{\text {gag-specific CD } 8+}$ cytotoxic T cells after administration of a virus-like particle vaccine in rhesus macaques. AIDS Res. Hum. Retroviruses 16, 273-282 (2000)

12. Schirmbeck, R., Bohm, W. \& Reimann, J. Virus-like particles induce MHC class I-restricted T-cell responses. Lessons learned from the hepatitis B small surface antigen. Intervirology 39, 111-119 (1996).

13. Buonaguro, L. et al. Induction of neutralizing antibodies and cytotoxic T lymphocytes in Balb/c mice immunized with virus-like particles presenting a gp120 molecule from a HIV-1 isolate of clade A. Antiviral Res. 54, 189-201 (2002)

14. Kaba, S. A. et al. Protective antibody and CD8+ T-cell responses to the Plasmodium falciparum circumsporozoite protein induced by a nanoparticle vaccine. PLoS ONE 7, e48304 (2012).

This paper shows SAPNs, consisting of multiple 125 amino acid-long polypeptide subunits engineered to express repetitively displayed $B$ cell and $T$ cell epitopes derived from an antigen of the causative agent of human malaria, activate long-lasting ( $>1$ year) and high-affinity protective cellular and humoral immune responses in a mouse model, which is an important proof of principle for progression to clinical trials using this novel vaccine platform.

15. Douglas, R. G. Jr. The heritage of hepatitis B vaccine. JAMA 276, 1796-1798 (1996).

16. Hilleman, M. R., McAleer, W. J., Buynak, E. B. \& McLean, A. A. The preparation and safety of hepatitis B vaccine. J. Infect. 7 (Suppl. 1), 3-8 (1983).

17. Buonaguro, L., Petrizzo, A., Tornesello, M. L. \& Buonaguro, F. M. Translating tumor antigens into cancer vaccines. Clin. Vaccine Immunol. 18, 23-34 (2011).

18. No, J. H., Kim, M. K., Jeon, Y. T., Kim, Y. B. \& Song, Y. S. Human papillomavirus vaccine: widening the scope for cancer prevention. Mol. Carcinog. 50 244-253 (2011)

19. Grun, J. L. \& Maurer, P. H. Different T helper cell subsets elicited in mice utilizing two different adjuvant vehicles: the role of endogenous interleukin 1 in proliferative responses. Cell. Immunol. 121, 134-145 (1989).

20. Jordan, M. B., Mills, D. M., Kappler, J., Marrack, P. \& Cambier, J. C. Promotion of B cell immune responses via an alum-induced myeloid cell population. Science 304, 1808-1810 (2004).

21. Bomford, R. The comparative selectivity of adjuvants for humoral and cell-mediated immunity. I. Effect on the antibody response to bovine serum albumin and sheep red blood cells of Freund's incomplete and complete adjuvants, alhydrogel, Corynebacterium parvum, Bordetella pertussis, muramyl dipeptide and saponin. Clin. Exp. Immunol. 39, 426-434 (1980).

22. Brewer, J. M. (How) do aluminium adjuvants work? Immunol. Lett. 102, 10-15 (2006)

23. Gupta, R. K., Rost, B. E., Relyveld, E. \& Siber, G. R. Vaccine Design: The Subunit and Vaccine Approach 229-248 (Plenum, 1995)

24. Wijburg, O. L. et al. The role of macrophages in the induction and regulation of immunity elicited by exogenous antigens. Eur. J. Immunol. 28, 479-487 (1998).

25. Naim, J. O., van Oss, C. J., Wu, W., Giese, R. F. \& Nickerson, P. A. Mechanisms of adjuvancy: I-metal oxides as adjuvants. Vaccine 15, 1183-1193 (1997).

26. Zanetti, A. R., Van Damme, P. \& Shouval, D. The global impact of vaccination against hepatitis $B$ : historical overview. Vaccine 26, 6266-6273 (2008).
27. Martinez-Sernandez, V. \& Figueiras, A

Central nervous system demyelinating diseases and recombinant hepatitis B vaccination: a critical systematic review of scientific production. J. Neurol. 20 Oct 2012 [epub ahead of print].

28. Boato, F. et al. Synthetic virus-like particles from selfassembling coiled-coil lipopeptides and their use in antigen display to the immune system. Angew. Chem Int. Ed. Engl. 46, 9015-9018 (2007).

This paper uses a lipopeptide monome incorporating a coiled-coil self-assembly motif in which the lipid tails form a central core to stabiliz the particle and enable the multivalent display of antigens in a nanometre-scale ( $\sim 20 \mathrm{~nm}$ ) synthetic VLP vaccine platform.

29. Mascola, J. R. \& Montefiori, D. C. The role of antibodies in HIV vaccines. Annu. Rev. Immunol. 28 413-444 (2010).

30. Wang, B. Z. et al. Incorporation of high levels of chimeric human immunodeficiency virus envelope glycoproteins into virus-like particles. J. Virol. $\mathbf{8 1}$, 10869-10878 (2007)

31. Riedel, T. et al. Synthetic virus-like particles and conformationally constrained peptidomimetics in vaccine design. Chembiochem 12, 2829-2836 (2011).

This report shows that synthetic VLPs can be engineered by structural vaccinology to stimulate immune responses targeted against narrowlydefined and critically exposed regions of an antigen, as for the induction of HIV-1-neutralizing antibodies against gp 120

32. Ghasparian, A. et al. Engineered synthetic virus-like particles and their use in vaccine delivery. Chembiochem 12, 100-109 (2011)

33. McBurney, S. P. \& Ross, T. M. Human immunodeficiency virus-like particles with consensus envelopes elicited broader cell-mediated peripheral and mucosal immune responses than polyvalent and monovalent Env vaccines. Vaccine 27, 4337-4349 (2009).

34. Scherer, E. M., Leaman, D. P., Zwick, M. B., McMichael, A. J. \& Burton, D. R. Aromatic residues at the edge of the antibody combining site facilitate viral glycoprotein recognition through membrane interactions. Proc. Natl Acad. Sci. USA 107 1529-1534 (2010)

35. Julien, J. P. et al. Ablation of the complementaritydetermining region $\mathrm{H} 3$ apex of the anti-HIV- 1 broadly neutralizing antibody $2 \mathrm{~F} 5$ abrogates neutralizing capacity without affecting core epitope binding. J. Virol. 84, 4136-4147 (2010)

36. Sanou, M. P., De Groot, A. S., Murphey-Corb, M., Levy, J. A. \& Yamamoto, J. K. HIV-1 vaccine trials: evolving concepts and designs. Open AIDS J. 6 , 274-288 (2012).

37. Look, M., Bandyopadhyay, A., Blum, J. S. \& Fahmy, T. M. Application of nanotechnologies for improved immune response against infectious diseases in the developing world. Adv. Drug Deliv. Rev. 62, 378-393 (2010).

38. Mundargi, R. C., Babu, V. R., Rangaswamy, V., Patel, P. \& Aminabhavi, T. M. Nano/micro technologies for delivering macromolecular therapeutics using poly(D,L-lactide-co-glycolide) and its derivatives. J. Control Release 125, 193-209 (2008). This article provides an overview of the concep and the importance of ordered and repetitive structural arrays expressed by VLPs and other nanoparticles for the optimal induction of B cell responses using the example of gp23, which is the major capsid protein of bacteriophage T4.

39. Bharali, D. J. et al. Novel nanoparticles for the delivery of recombinant hepatitis $\mathrm{B}$ vaccine. Nanomedicine 4, 311-317 (2008)

40. Chou, H. Y. et al. Hydrogel-delivered GM-CSF overcomes nonresponsiveness to hepatitis $B$ vaccine through the recruitment and activation of dendritic cells. J. Immunol. 185, 5468-5475 (2010).

41. Raman, S., Machaidze, G., Lustig, A., Aebi, U. \& Burkhard, P. Structure-based design of peptides that self-assemble into regular polyhedral nanoparticles. Nanomedicine 2, 95-102 (2006).

42. Baschong W., Hasler, L, Haner, M., Kistler, J \& Aebi, $U$. Repetitive versus monomeric antigen presentation: direct visualization of antibody affinity and specificity. J. Struct. Biol. 143, 258-262 (2003).

43. Schroeder, U. et al. Peptide nanoparticles serve as a powerful platform for the immunogenic display of poorly antigenic actin determinants. J. Mol. Biol. 386 , 1368-1381 (2009).
44. Pimentel, T. A. et al. Peptide nanoparticles as novel immunogens: design and analysis of a prototypic severe acute respiratory syndrome vaccine. Chem. Biol. Drug Des. 73, 53-61 (2009).

45. Babapoor, S. et al. A novel vaccine using nanoparticle platform to present immunogenic M2e against avian influenza infection. Influenza Res. Treat. http://dx.doi.org/10.1155/2011/126794 (2012)

46. Kaba, S. A. et al. A nonadjuvanted polypeptide nanoparticle vaccine confers long-lasting protection against rodent malaria. J. Immunol. 183. 7268-7277 (2009).

47. Wahome, N. et al. Conformation-specific display of $4 \mathrm{E} 10$ and 2F5 epitopes on self-assembling protein nanoparticles as a potential HIV vaccine. Chem. Biol. Drug Des. 80, 349-357 (2012)

48. O'Hagan, D. T., Tsai, T. \& Reed, S. in Influenza Vaccines for the Future 2nd edn (eds Rappuoli, R. \& Del Giudice, G.) 327-357 (Springer, 2011).

49. Vogel, F. R., Caillet, C., Kusters, I. C. \& Haensler, J. Emulsion-based adjuvants for influenza vaccines. Expert Rev. Vaccines 8, 483-492 (2009).

50. Calabro, S. et al. Vaccine adjuvants alum and MF59 induce rapid recruitment of neutrophils and monocytes that participate in antigen transport to draining lymph nodes. Vaccine 29, 1812-1823 (2011).

51. Seubert, A., Monaci, E., Pizza, M., O'Hagan, D. T. \& Wack, A. The adjuvants aluminum hydroxide and MF59 induce monocyte and granulocyte chemoattractants and enhance monocyte differentiation toward dendritic cells. J. Immunol. 180, 5402-5412 (2008).

52. Wack, A. et al. Combination adjuvants for the induction of potent, long-lasting antibody and T-cel responses to influenza vaccine in mice. Vaccine $\mathbf{2 6}$ 552-561 (2008)

53. Bernstein, D. I. et al. Effects of adjuvants on the safety and immunogenicity of an avian influenza $\mathrm{H} 5 \mathrm{~N} 1$ vaccine in adults. J. Infect. Dis. 197, 667-675 (2008).

54. Schultze, V. et al. Safety of MF59 adjuvant. Vaccine 26, 3209-3222 (2008)

55. Barchfeld, G. L. et al. The adjuvants MF59 and LT-K63 enhance the mucosal and systemic immunogenicity of subunit influenza vaccine administered intranasally in mice. Vaccine 17, 695-704 (1999).

56. Boyce, T. G. et al. Safety and immunogenicity of adjuvanted and unadjuvanted subunit influenza vaccines administered intranasally to healthy adults. Vaccine 19, 217-226 (2000).

57. Stanberry, L. R. et al. Safety and immunogenicity of a novel nanoemulsion mucosal adjuvant W805EC combined with approved seasonal influenza antigens. Vaccine 30, 307-316 (2012).

58, Makidon, P. E. et al. Pre-clinical evaluation of a novel nanoemulsion-based hepatitis B mucosal vaccine. PLOS ONE 3, e2954 (2008)

59. Makidon, P. E. et al. Nanoemulsion mucosal adjuvant uniquely activates cytokine production by nasa ciliated epithelium and induces dendritic cell trafficking. Eur. J. Immunol. 42, 2073-2086 (2012).

60. Green, D. R., Ferguson, T., Zitvogel, L. \& Kroemer, G. Immunogenic and tolerogenic cell death. Nature Rev. Immunol. 9, 353-363 (2009).

This article provides an overview of immunogenic cell death as a concept used to describe signals produced by dying cells or expressed on the cell surface that lead to the activation of innate and adaptive immune responses rather than to the induction of unresponsiveness or tolerance. This is an important consideration for particular types of nanoparticles that are known to induce apoptosis or necrosis as this could potentially be related to vaccine immunogenicity.

61. Obeid, M. et al. Calreticulin exposure dictates the immunogenicity of cancer cell death. Nature Med. 13 54-61 (2007)

62. Hamouda, T. et al. A novel surfactant nanoemulsion with broad-spectrum sporicidal activity against Bacillus species. J. Infect. Dis. 180, 1939-1949 (1999).

63. Hamouda, T. \& Baker, J. R. Jr. Antimicrobial mechanism of action of surfactant lipid preparations in enteric Gram-negative bacilli. J. Appl. Microbiol. 89. 397-403 (2000)

64. Hamouda, T. et al. A novel surfactant nanoemulsion with a unique non-irritant topical antimicrobial activity against bacteria, enveloped viruses and fungi. Microbiol. Res. 156, 1-7 (2001).

65. Donovan, B. W. et al. Prevention of murine influenza A virus pneumonitis by surfactant nano-emulsions. Antivir. Chem. Chemother. 11, 41-49 (2000). 
66. Bielinska, A. U. et al. A novel, killed-virus nasal vaccinia virus vaccine. Clin. Vaccine Immunol. 15 348-358 (2008)

67. Lindell, D. M. et al. A novel inactivated intranasal respiratory syncytial virus vaccine promotes viral clearance without Th2 associated vaccine-enhanced disease. PLOS ONE 6, e21823 (2011).

68. Myc, A. et al. Development of immune response that protects mice from viral pneumonitis after a single intranasal immunization with influenza A virus and nanoemulsion. Vaccine 21, 3801-3814 (2003).

69. Makidon, P. E. et al. Induction of immune response to the $17 \mathrm{kDa}$ OMPA Burkholderia cenocepacia polypeptide and protection against pulmonary infection in mice after nasal vaccination with an OMP nanoemulsion-based vaccine. Med. Microbiol. Immunol. 199, 81-92 (2010).

70. Bielinska, A. U. et al. Mucosal immunization with a novel nanoemulsion-based recombinant anthrax protective antigen vaccine protects against Bacillus anthracis spore challenge. Infect. Immun. 75 , 4020-4029 (2007).

71. Bielinska, A. U. et al. Nasal immunization with a recombinant HIV gp 120 and nanoemulsion adjuvant produces Th 1 polarized responses and neutralizing antibodies to primary HIV type 1 isolates. AIDS Res. Hum. Retroviruses 24, 271-281 (2008).

72. Durrer, P. et al. Mucosal antibody response induced with a nasal virosome-based influenza vaccine. Vaccine 21, 4328-4334 (2003).

73. Kamath, A. T. et al. A liposome-based mycobacterial vaccine induces potent adult and neonatal multifunctional T cells through the exquisite targeting of dendritic cells. PLOS ONE 4, e5771 (2009).

74. Christensen, D., Korsholm, K. S., Andersen, P. \& Agger, E. M. Cationic liposomes as vaccine adjuvants Expert Rev. Vaccines 10, 513-521 (2011)

75. Henriksen-Lacey, M. et al. Liposomal cationic charge and antigen adsorption are important properties for the efficient deposition of antigen at the injection site and ability of the vaccine to induce a $\mathrm{CMI}$ response. J. Control Release 145, 102-108 (2010).

This study evaluates the biodistribution of separately radiolabelled lipids and antigens to show the gradual release or depot effect to be a crucial delivery mechanism, in combination with innate activation and monocyte infiltration, for cationic liposome-based vaccines after intramuscular administration to mice.

76. Henriksen-Lacey, M. et al. Comparison of the depot effect and immunogenicity of liposomes based on dimethyldioctadecylammonium (DDA), $3 \beta-[N$ $\left(N^{\prime}, N^{\prime}\right.$-Dimethylaminoethane)carbomyl] cholesterol (DC-Chol), and 1,2-Dioleoyl-3-trimethylammonium propane (DOTAP): prolonged liposome retention mediates stronger Th1 responses. Mol. Pharm. 8, 153-161 (2011)

77. Brunel, F., Darbouret, A. \& Ronco, J. Cationic lipid DC-Chol induces an improved and balanced immunity able to overcome the unresponsiveness to the hepatitis B vaccine. Vaccine 17, 2192-2203 (1999).

78. Werninghaus, K. et al. Adjuvanticity of a synthetic cord factor analogue for subunit Mycobacterium tuberculosis vaccination requires $\mathrm{FcR} \gamma$ Syk-Card9-dependent innate immune activation. J. Exp. Med. 206, 89-97 (2009).

79. Bal, S. M., Hortensius, S., Ding, Z., Jiskoot, W. \& Bouwstra, J. A. Co-encapsulation of antigen and Tolllike receptor ligand in cationic liposomes affects the quality of the immune response in mice after intradermal vaccination. Vaccine 29, 1045-1052 (2011).

80. Zhou, S., Kawakami, S., Yamashita, F. \& Hashida, M Intranasal administration of CpG DNA lipoplex prevents pulmonary metastasis in mice. Cancer Lett. 287, 75-81 (2010).

81. Zaks, K et al. Efficient immunization and crosspriming by vaccine adjuvants containing TLR3 or TLR9 agonists complexed to cationic liposomes. J. Immunol. 176, 7335-7345 (2006).

82. Whitmore, M. M., Li, S., Falo, L. Jr \& Huang, L. Systemic administration of LPD prepared with $\mathrm{CpC}$ oligonucleotides inhibits the growth of established pulmonary metastases by stimulating innate and acquired antitumor immune responses. Cance Immunol. Immunother. 50, 503-514 (2001)

83. Zolnik, B. S., Gonzalez-Fernandez, A., Sadrieh, N. \& Dobrovolskaia, M. A. Nanoparticles and the immune system. Endocrinology 151, 458-465 (2010).
84. Nielsen, G. D., Roursgaard, M., Jensen, K. A., Poulsen, S. S. \& Larsen, S. T. In vivo biology and toxicology of fullerenes and their derivatives. Basic Clin. Pharmacol. Toxicol. 103, 197-208 (2008).

85. Mitchell, L. A. et al. Pulmonary and systemic immune response to inhaled multiwalled carbon nanotubes. Toxicol. Sci. 100, 203-214 (2007).

86. Bosi, S., Da Ros, T., Spalluto, G. \& Prato, M Fullerene derivatives: an attractive tool for biological applications. Eur. J. Med. Chem. 38, 913-923 (2003)

87. Ryan, J. J. et al. Fullerene nanomaterials inhibit the allergic response. J. Immunol. 179, 665-672 (2007).

88. Tkach, A. V. et al. Direct effects of carbon nanotubes on dendritic cells induce immune suppression upon pulmonary exposure. ACS Nano 5, 5755-5762 (2011).

89. Mitchell, L. A., Lauer, F. T., Burchiel, S. W. \& McDonald, J. D. Mechanisms for how inhaled multiwalled carbon nanotubes suppress systemic immune function in mice. Nature Nanotechnol. 4, 451-456 (2009)

This work explores the mechanisms by which multi-walled carbon nanotubules have a direct effect on immunomodulation.

90. Liu, R. et al. Research on the bioactivities of C60-dexamethasone. J. Nanosci. Nanotechnol. 9, 3171-3176 (2009)

91. Konduru, N. V. et al. Phosphatidylserine targets single-walled carbon nanotubes to professional phagocytes in vitro and in vivo. PLOS ONE 4, e4398 (2009)

92. Muller, R. H. \& Keck, C. M. Challenges and solutions for the delivery of biotech drugs - a review of drug nanocrystal technology and lipid nanoparticles. J. Biotechnol. 113, 151-170 (2004).

93. Shen, L. J. \& Wu, F. L. Nanomedicines in renal transplant rejection - focus on sirolimus. Int. J. Nanomed. 2, 25-32 (2007).

94. Kaminskas, L. M., McLeod, V. M., Porter, C. J. ¿ Boyd, B. J. Association of chemotherapeutic drugs with dendrimer nanocarriers: an assessment of the merits of covalent conjugation compared to noncovalent encapsulation. Mol. Pharm. 9, 355-373 (2012).

95. Kannan, S. et al. Dendrimer-based postnatal therapy for neuroinflammation and cerebral palsy in a rabbit model. Sci. Transl. Med. 4, 130ra146 (2012). This article shows that the beneficial effect of the anti-inflammatory agent NAC is enhanced by polyamidoamine dendrimers and suggests that the enhanced effect is due to the enhanced delivery of the anti-inflammatory agent.

96. Shaunak, S. et al. Polyvalent dendrimer glucosamine conjugates prevent scar tissue formation. Nature Biotech. 22, 977-984 (2004).

97. Barata, T. S., Teo, I., Brocchini, S., Zloh, M. \& Shaunak, S. Partially glycosylated dendrimers block MD-2 and prevent TLR4-MD-2-LPS complex mediated cytokine responses. PLoS Comput. Biol. 7, e1002095 (2011)

98. Teo, l. et al. Preventing acute gut wall damage in infectious diarrhoeas with glycosylated dendrimers. EMBO Mol. Med 4, 866-881 (2012).

99. Shukla, N. M. et al. Potent adjuvanticity of a pure TLR7-agonistic imidazoquinoline dendrimer. PLOS ONE 7, e43612 (2012).

100. Higaki, M., Ishihara, T., Izumo, N., Takatsu, M. \& Mizushima, Y. Treatment of experimental arthritis with poly(D, L-lactic/glycolic acid) nanoparticles encapsulating $\beta$-methasone sodium phosphate. Ann. Rheum. Dis. 64, 1132-1136 (2005).

101. Buyuktimkin, B. et al. Vaccine-like controlled-release delivery of an immunomodulating peptide to treat experimental autoimmune encephalomyelitis. Mol. Pharm. 9, 979-985 (2012).

102. Park, J. et al. Modulation of CD4+ T lymphocyte lineage outcomes with targeted, nanoparticlemediated cytokine delivery. Mol. Pharm. 8, 143-152 (2011)

103. Slutter, B. et al. Nasal vaccination with $\mathrm{N}$-trimethyl chitosan and PLGA based nanoparticles: nanoparticle characteristics determine quality and strength of the antibody response in mice against the encapsulated antigen. Vaccine 28, 6282-6291 (2010)

104. Baca-Estrada, M. E., Foldvari, M. \& Snider, M Induction of mucosal immune responses by administration of liposome-antigen formulations and interleukin-12.J. Interferon Cytokine Res. 19 455-462 (1999).
105. Keijzer, C. et al. PLGA, PLGA-TMC and TMC-TPP nanoparticles differentially modulate the outcome of nasal vaccination by inducing tolerance or enhancing humoral immunity. PLoS ONE 6, e26684 (2011).

This work shows that specific properties of a nanoparticle, including charge and route of administration, have a differential effect on the immune response.

106. Landesman-Milo, D. \& Peer, D. Altering the immune response with lipid-based nanoparticles. J. Control Release 161, 600-608 (2012).

107. Musacchio, T. \& Torchilin, V. P. Recent developments in lipid-based pharmaceutical nanocarriers Front. Biosci. 16, 1388-1412 (2011).

108. Gaca, J. G. et al. Prevention of acute lung injury in swine: depletion of pulmonary intravascular macrophages using liposomal clodronate. J. Surg. Res. 112, 19-25 (2003)

109. Richards, P. J., Williams, B. D. \& Williams, A. S. Suppression of chronic streptococcal cell wall-induced arthritis in Lewis rats by liposomal clodronate. Rheumatology 40, 978-987 (2001).

110. Epstein, H. et al. Preparation of alendronate liposomes for enhanced stability and bioactivity: in vitro and in vivo characterization. AAPS J. 10 , 505-515 (2008)

111. Zheng, X. et al. A novel in vivo siRNA delivery system specifically targeting dendritic cells and silencing CD40 genes for immunomodulation. Blood 113 2646-2654 (2009).

112. Koo, O. M., Rubinstein, I. \& Onyuksel, H. Actively targeted low-dose camptothecin as a safe, long-acting disease-modifying nanomedicine for rheumatoid arthritis. Pharm. Res. 28, 776-787 (2011).

113. Khaja, F. A., Koo, O. M. \& Onyuksel, H. Nanomedicines for inflammatory diseases. Methods Enzymol. 508, 355-375 (2012)

114. Wang, S. H., Fan, Y., Makidon, P. E., Cao, Z. \& Baker, J. R. Induction of immune tolerance in mice with a novel mucosal nanoemulsion adjuvant and self-antigen. Nanomedicine 7, 867-876 (2012). This study shows that nanoemulsion-enhanced uptake of self antigens results in a decreased humoral immune response, upregulation of FOXP3 and TGF $\beta$ expression, and increased $\mathrm{T}_{\text {nell }}$ cell activity.

115. Bielinska, A. U. et al. Induction of Th 17 cellular immunity with a novel nanoemulsion adjuvant. Crit. Rev. Immunol. 30, 189-199 (2010).

116. McAleer, J. P. \& Vella, A. T. Educating CD4 T cells with vaccine adjuvants: lessons from LPSsaccharide. Trends Immunol. 31, 429-435 (2010).

117. Wiersinga, W. J. Current insights in sepsis: from pathogenesis to new treatment targets. Curr. Opin. Crit. Care 17, 480-486 (2011).

118. Biswas, S. K \& Lopez-Collazo, E. Endotoxin tolerance: new mechanisms, molecules and clinical significance. Trends Immunol. 30, 475-487 (2009).

119. Mata-Haro, V. et al. The vaccine adjuvant monophosphoryl lipid A as a TRIF-biased agonist of TLR4 Science 316, 1628-1632 (2007).

120. Dubensky, T. W. Jr \& Reed, S. G. Adjuvants for cancer vaccines. Semin. Immunol. 22, 155-161 (2010).

21. Yosef, N. et al. Dynamic regulatory network controlling TH1 7 cell differentiation. Nature 496, 461-468 (2013). In this paper, the silicon composition, needle-like shape and dimensions of vertical-oriented nanowires are used in a new way to penetrate the T cell membrane without cellular toxicity to introduce siRNA into the cytosol as a means to evaluate the network of genes regulating $T_{H} 17$ cell differentiation.

122. US National Nanotechnology Initiative. What is nanotechnology? Nano.gov [online], http://www.nano. gov/nanotech-101/what/definition (2012).

123. US Food and Drug Administration. Considering whether an FDA-regulated product involves the application of nanotechnology: guidance for industry. FDA [online], http://www.FDA.fda.gov/ Regulatorylnformation/Guidances/ucm 257698.htm (2011).

124. European Medicines Agency. Nanotechnology. [online], http://www.ema.europa.eu/ema/index. jsp?curl = pages $/$ special topics $/$ general $/$ general content 000345.jsp\&mid = WC000340b000301 acO 05800baed000349\&jsenabled = true (2012).

125. Tao, Y. \& Zhang, L. Characterization of polysaccharideprotein complexes by size-exclusion chromatography combined with three detectors. Carbohydr. Res. 343 2251-2257 (2008). 
126. Erickson, H. P. Size and shape of protein molecules at the nanometer level determined by sedimentation, ge filtration, and electron microscopy. Biol. Proced. Online 11, 32-51 (2009).

127. Choe, J., Kelker, M. S. \& Wilson, I. A. Crystal structure of human toll-like receptor 3 (TLR3) ectodomain. Science 309, 581-585 (2005)

128. Klein, J. S. et al. Examination of the contributions of size and avidity to the neutralization mechanisms of the anti-HIV antibodies b12 and 4E10. Proc. Natl Acad. Sci. USA 106, 7385-7390 (2009).

129. Arechaga, I. et al. Structural characterization of the TCR complex by electron microscopy. Int. Immunol. 22, 897-903 (2010)

130. Bachmann, M. F. \& Jennings, G. T. Vaccine delivery: a matter of size, geometry, kinetics and molecular patterns. Nature Rev. Immunol. 10, 787-796 (2012)

131. Alexopoulos, C. J., Mims, C. W. \& M., B. Introductory Mycology (John Wiley and Sons, 1996).

132. Yaeger, R. G. in Medical microbiology 4th edn Ch. 77 (ed. Baron, S.) (Univ. of Texas Medical Branch at Galveston, 1996).

133. Lipscomb, M. F. \& Masten, B. J. Dendritic cells: immune regulators in health and disease. Physiol. Rev. 82, 97-130 (2002).

134. Krombach, F. et al. Cell size of alveolar macrophages: an interspecies comparison. Environ. Health Perspect. 105 (Suppl. 5), 1261-1263 (1997).

135. DeFranco, A. L. Structure and function of the B cell antigen receptor. Annu. Rev. Cell Biol. 9, 377-410 (1993).

136. Weiss, A. Structure and function of the T cell antigen receptor. J. Clin. Invest. 86, 1015-1022 (1990).
137. Zucker-Franklin, D. Atlas of Blood Cells: Function and Pathology (Lea \& Febiger, 1981).

138. Weller, P. F. Eosinophils: structure and functions Curr. Opin. Immunol. 6, 85-90 (1994).

139. Hamdy, S. et al. Co-delivery of cancer-associated antigen and Toll-like receptor 4 ligand in PLGA nanoparticles induces potent $\mathrm{CD} 8{ }^{+} \mathrm{T}$ cell-mediated anti-tumor immunity. Vaccine 26, 5046-5057 (2008).

140. Zhang, Z. et al. Induction of anti-tumor cytotoxic T cell responses through PLGA-nanoparticle mediated antigen delivery. Biomaterials 32, 3666-3678 (2011)

141. Uenaka, A. et al. T cell immunomonitoring and tumor responses in patients immunized with a complex of cholesterol-bearing hydrophobized pullulan (CHP) and NY-ESO-1 protein. Cancer Immun. 7, 9 (2007).

142. Kitano, S. et al. HER2-specific T-cell immune responses in patients vaccinated with truncated HER2 protein complexed with nanogels of cholesteryl pullulan. Clin. Cancer Res. 12, 7397-7405 (2006).

143. Nochi, T. et al. Nanogel antigenic protein-delivery system for adjuvant-free intranasal vaccines. Nature Mater. 9, 572-578 (2010).

144. Gu, X. G. et al. A novel hydrophobized polysaccharide/ oncoprotein complex vaccine induces in vitro and in vivo cellular and humoral immune responses against HER2-expressing murine sarcomas. Cancer Res. 58, 3385-3390 (1998).

145. Ikuta, Y. et al. Presentation of a major histocompatibility complex class 1 -binding peptide by monocyte-derived dendritic cells incorporating hydrophobized polysaccharide-truncated HER2 protein complex: implications for a polyvalent immuno-cell therapy. Blood 99, 3717-3724 (2002).
146. Vangala, A. et al. Comparison of vesicle based antigen delivery systems for delivery of hepatitis B surface antigen. J. Control Release 119, 102-110 (2007).

147. Frazer, I. H. et al. Phase 1 study of HPV16-specific immunotherapy with E6E7 fusion protein and ISCOMATRIX adjuvant in women with cervical intraepithelial neoplasia. Vaccine 23, 172-181 (2004).

148. Maraskovsky, E. et al. NY-ESO-1 protein formulated in ISCOMATRIX adjuvant is a potent anticancer vaccine inducing both humoral and CD8 + T-cell-mediated immunity and protection against NY-ESO-1 + tumors. Clin. Cancer Res. 10, 2879-2890 (2004).

149. Mitchell, J. E. et al. The presumptive phosphatidylserine receptor is dispensable for innate anti-inflammatory recognition and clearance of apoptotic cells. J. Biol. Chem. 281, 5718-5725 (2006).

Acknowledgements

The authors thank A. Myc and A. Bielinska, University of Michigan, USA, for helpful discussions of dendrimer-based technologies.

\section{Competing interests statement}

The authors declare competing financial interests: see Web version for details.

DATABASES

Michigan Nanotechnology Institute for Medicine and

Biological Sciences: www.nano.med.umich.edu

ALL LINKS ARE ACTIVE IN THE ONLINE PDF 
ERRATUM

Applications of nanotechnology for immunology

Douglas M. Smith, Jakub K. Simon and James R. Baker Jr

Nature Reviews Immunology 13, 592-605 (2013)

In the version of this Review that was initially published, the reference citations in Tables 1-3 were not accurate. This error

has been corrected in the online HTML and PDF versions of the article. Nature Reviews Immunology apologizes for this error. 